\title{
A Guideline Tool for Ongoing Product Evaluation in Small and Medium-Sized Enterprises
}

\author{
Fouad Abdulameer Salman, Aziz Bin Deraman, Masita Binti Abdul Jalil \\ School of Informatics and Applied Mathematics \\ Universiti Malaysia Terengganu (UMT)
}

\begin{tabular}{l} 
Article Info \\
\hline Article history: \\
Received Feb 7, 2017 \\
Revised Jun 20, 2017 \\
Accepted Jul 10, 2017 \\
\hline Keyword: \\
Usability \\
Usability evaluation \\
Software development process \\
ISO standards \\
SME
\end{tabular}

\begin{abstract}
As consumer demand for user friendly software increases, usability evaluation is crucial to develop software systems which are easy to learn and use. However, implementation of usability evaluation is challenging for small and medium-sized enterprises (SMEs) due to factors such as lack of technical expertise, knowledge and experience of methods and standards. This results in neglect, or poorly executed evaluations of projects, resulting in software that disappoints and frustrates clients. To overcome this loss of competitiveness, we propose here a visual incorporation tool derived from ISO standards that would assist software development teams in SMEs in understanding and implementing usability evaluations. It shows fundamental Usability Engineering (UE) and Software Engineering (SE) activities and artifacts relevant to the usability evaluation and software development process, with potential incorporation points being highlighted. Dependencies and relationships are shown by links between activities and artifacts. Additionally, convergent artifacts of both disciplines were identified and shown. Evaluation of the proposed tool was based on the questionnaire results of software development practitioners from SMEs.
\end{abstract}

Copyright (C) 2017Institute of Advanced Engineering and Science. All rights reserved.

Corresponding Author:

Aziz Bin Deraman,

School of Informatics and Applied Mathematics,

Universiti Malaysia Terengganu (UMT),

$21030 \mathrm{~K}$. Terengganu, Terengganu Malaysia.

Email: a.d@umt.edu.my

\section{INTRODUCTION}

The marketability of a product in a competitive business environment relies heavily on customer acceptance and satisfaction. For instance, the purchase decisions of client companies are influenced at least in part by a product's ease of use, which is termed usability [1]. A functional software is less competitive if it has poor usability [2], [3]. Thus, the usability concept is gaining attention in the work processes and business culture of the technology sector. However, the implementation of the usability evaluation presents challenges due to the variation in software companies from size, market sector, time in business, management style, location, to the type of services and products provided [4].

The challenge for the SMEs of software development stems from the lack of technical expertise or the required resources (e.g. sufficient number of employees, financial resources, and deadlines set by customers) to implement usability evaluation [5], [6]. Current studies show a relatively limited adoption of usability evaluation methods in SMEs [7], [8], [9], [10], [11]. This is a vicious cycle as the lack of knowledge and experience towards usability evaluation methods and standards compromises the usability of produced software and thus reduces competitiveness. Furthermore, systematic approaches for integrating usability are uncommon compared to the standards-based approaches. Nonetheless, standards define predictable and repeatable processes and form a common knowledge base which greatly helps companies to identify and plan timely, effective usability activities in sync with ongoing software design processes. Unfortunately, software 
development teams in SMEs tend to perceive the international standards negatively, i.e that standards are biased to large companies, and lose all the mentioned benefits by opposing to their use [5].

In this paper, we propose a tool derived from international standards as a guide for potential incorporation points (activities, and artifacts) between the usability evaluation and software development process (T-GIUESE). The integration approach was chosen to give equal consideration to both disciplines by way of identifying the standards that from the basis for integration. T-GIUESE results from identification of common activities and establishment of whereas common artifacts and dependencies. Through this tool, software development teams will be able to set, prioritize, and evaluate usability aspects smoothly during their projects as well as learn to use and understand the standards- and methods-based usability evaluation.

\section{ISO STANDARDS IN UE AND SE}

This section provides the background knowledge on the ISO international standards related to UE and SE, to show the basis of selecting appropriate standards for the proposed tool. The following sections discuss each standard in detail.

\subsection{Standards in Software Engineering}

Software Engineering (SE) standards define the rules, guidelines and properties of process elements that are recommended for software development. As such, SE standards define a framework for SE models on a higher level of abstraction. This ultimately supports the consistency, compatibility and exchangeability of information, leading to improved communication and product quality.

To reach the desired outcomes above, SE models should comply with the conditions defined by standards. However, both standards and SE Models cannot be applied directly and need to be adapted to corresponding organizational conditions. An SE model can only be considered a software development process after being fitted to organizational aspects, and there after put to practice. Thus, operation processes result from both an underlying SE model and the organizational implementation of activities. There are multiple international standards for SE, but only those concerning development processes will be discussed. Table 1 below lists and describes the international standards and technical reports for SE.

\subsection{Standards in Usability Engineering}

Usability Engineering (UE) has standards similar to Software Engineering (SE), which also serves as a framework to ensure consistency, compatibility, exchangeability, and quality consistent with defined standards. However, UE standards are user centric and focused on the construction of usable solutions. According to Nigel Bevan [15], there are 4 classes of usability related standards, dealing with: 1 . The use of the product, 2. user interface and interaction, 3. the product development process, and 4. the capability of an organization to apply user-centric designs. Among these classes, our concern is mainly on the product development process, specifically, the planning of a usability process and the incorporation of usability activities in the development of interactive systems. Table 2 below lists and describes the international standards and technical reports related to usability evaluation (UE).

Table 1. International standards of SE

\begin{tabular}{|c|c|c|}
\hline $\begin{array}{l}\text { Software } \\
\text { engineering } \\
\text { Std }\end{array}$ & Year & Description \\
\hline $\begin{array}{c}\text { ISO/IEC } \\
15288 \text { [12] }\end{array}$ & 2015 & $\begin{array}{l}\text { This standard establishes a common framework for describing the life cycle of human created systems. } \\
\text { It covers } 25 \text { processes with numerous activities and artifacts to be applied while acquiring a software } \\
\text { product/service, and the development or other similar processes of systems products. }\end{array}$ \\
\hline $\begin{array}{c}\text { ISO/IEC } \\
12207 \text { [13] }\end{array}$ & 2002 & $\begin{array}{l}\text { This standard establishes a common framework for describing the life cycle of software. It contains } \\
\text { processes, activities, and artifacts to be applied while acquiring a software product/service, and the } \\
\text { development or other similar processes of software products. }\end{array}$ \\
\hline $\begin{array}{c}\text { ISO/IEC } \\
15504[14]\end{array}$ & $\begin{array}{l}2003- \\
2006\end{array}$ & $\begin{array}{l}\text { This standard is known as SPICE ('Software Process Improvement and Capability Determination'). It } \\
\text { covers show to evaluate the maturity of a software development process in an organization and } \\
\text { provides comprehensive information on the concepts of process assessment. }\end{array}$ \\
\hline
\end{tabular}


Table 2. International standards of UE

\begin{tabular}{crl}
\hline Usability Std & Year & Description \\
\hline $\begin{array}{c}\text { ISO 9241-210 } \\
\text { [16] }\end{array}$ & $\mathbf{2 0 1 0}$ & $\begin{array}{l}\text { This standard covers usability evaluation principles, activities, and artifacts throughout the life } \\
\text { cycle of interactive systems. It serves as an ideal to alleviate usability problems from a user } \\
\text { centric perspective, helping to make systems usable and useful by focusing on users needs and } \\
\text { requirements. }\end{array}$ \\
ISO TR 16982 & $\mathbf{2 0 0 2}$ & $\begin{array}{l}\text { This technical report covers information on usability evaluation methods. It explains the impact } \\
\text { of life cycle stage and individual project characteristics on the selection of evaluation methods } \\
\text { with examples of use in context. }\end{array}$ \\
[17] & $\mathbf{2 0 0 1}$ & $\begin{array}{l}\text { This standard specifies the process used for software product evolution. It focuses on metrics and } \\
\text { associated methods of using measurement results for specific software product evaluations. }\end{array}$ \\
\hline [18]
\end{tabular}

From the standards in Tables 1 and 2, we can infer that UE and SE are very similar, thus it seems possible to incorporate the usability evaluation into the software development process. The ISO 9241 standard seems to serve as a suitable basis to support usability evaluation throughout the software development process, as it contains guidelines for planning and managing projects that design and develop the interactive systems. Similarly for software development, the ISO/IEC 15288 standard seems to be a proper basis as it contains guidelines for the definition, control and improvement of the life cycle processes used within an organization or a project. As shown in Figure 1, the ISO/IEC15288 and ISO ISO 9241 standards have been chosen to construct a solid basis for integration. The activities and articles of these standards used to construct the comprehensive model are discussed in detail in the following section.

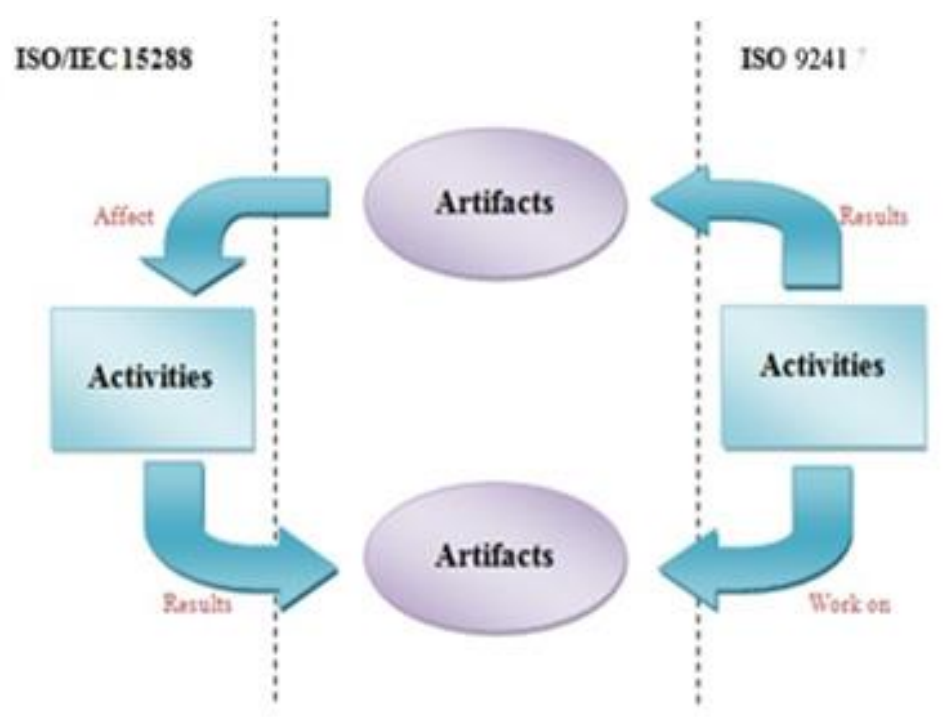

Figure 1. The general incorporation model

\section{MODEL OF USABILITY EVALUATION INCORPORATION}

This section discusses the proposed model for incorporating the usability evaluation in the software development process. The basis of the incorporation model is a list of activities and artifacts constructed from carefully selected and analyzed ISO standards from the usability evaluation and software development processes, ultimately aiming to operationalize these standards and thus simplifying its implementation. The incorporation was implemented through three main stages i.e 1. Mapping potential incorporation points 2. Linking dependencies of activities and artifacts and 3. Displaying convergent artifacts, which are discussed in detail below.

Firstly, based on the overlap between the usability evaluation and software development activities (see Figure 1 above), the potential incorporation points were mapped. Secondly, the dependencies of activities and artifacts from both fields are linked. Interlinking the usability and software development activities is insufficient due to necessary considerations for required information flows and artifacts. Therefore, a concrete basis of artifacts was extracted from the chosen standards for further investigation. Examining the dependencies of those activities and artifacts shows the information flow between the activities for each process. Input and output artifacts are defined for each process to explicitly show what is 
used and produced for each activity. Figure 2 shows an excerpt of the represented and distributed artifacts within activities of each process, numbered according to their position in the origin list and labeled accordingly as either the input or output (I, O). Thirdly, the convergent artifacts for both processes were identified and displayed to hint at the prospective incorporation points. The artifacts converging on the same activities in the software development process were listed based on the previously determined interlinking between usability and develop activities. The artifacts linked with the software development activities are labeled input (I) and/or output (O) as some are applicable to more than one activity. For instance, "results of the evaluation" is frequently labeled as output and input in different phases. The activities were numbered by their position in the origin list, indicating to which phase of the development process they belong. The artifacts are presented as output and input $(\mathrm{I}, \mathrm{O})$ alongside their numbers.
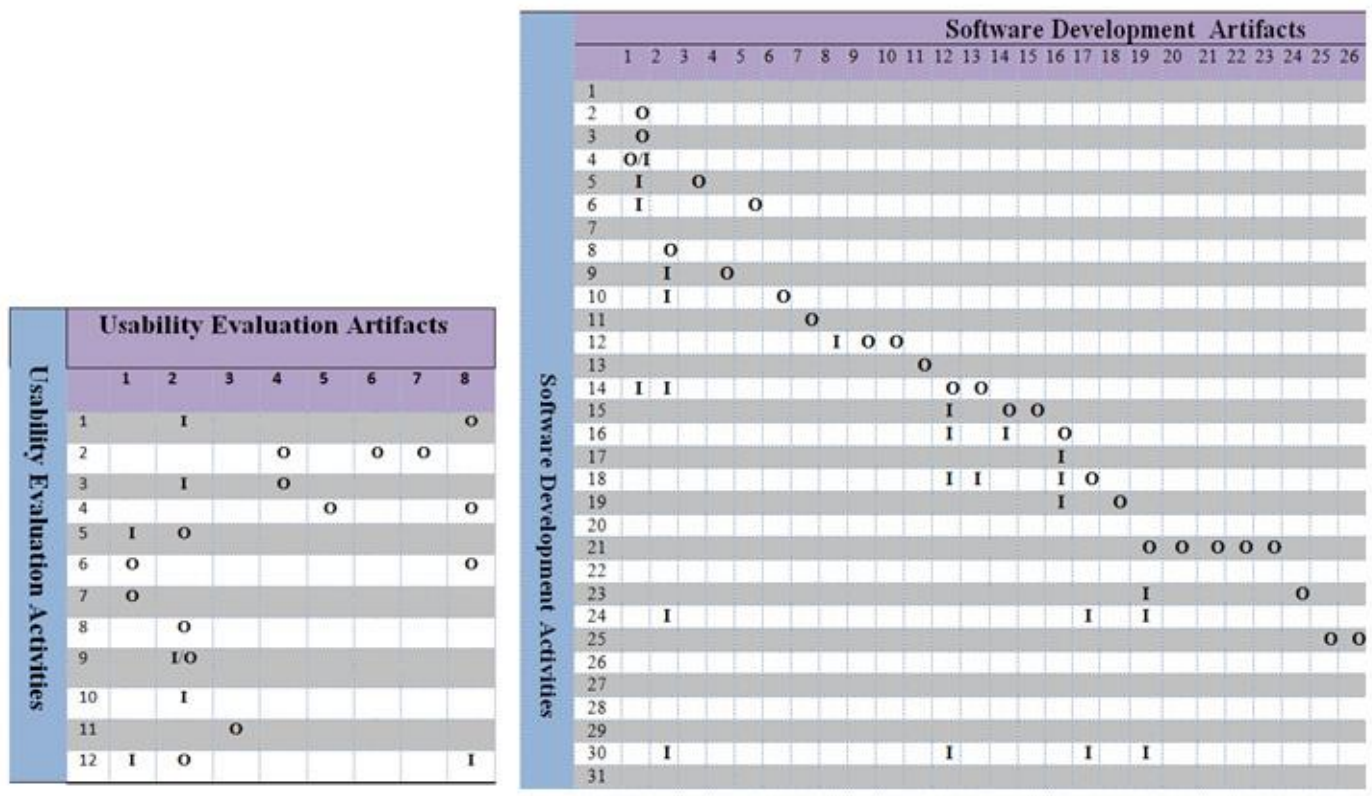

Figure 2. Excerpt of information exchange of artifacts within activities

\section{T-GIUESE}

This section visualizes the proposed incorporation tool, T-GIUESE, which contains 3 phases i.e: potential incorporation points, dependencies of activities and artifacts, and convergence points of artifacts for both UE and SE disciplines. These are presented as lists with connecting arrows, where for clarity, different aspects were presented separately, i.e requirements, design, implementation, and testing (software development activities). Directed arrows were used to highlight incorporation points, whereas colored arrows connect corresponding artifacts between the activities. For instance, the information exchange of artifacts are presented as: black $=$ output, blue $=$ input, and brown $=$ input/output, to simplify the visual model. An excerpt of the visualized model is shown in Figures 3, 4. 


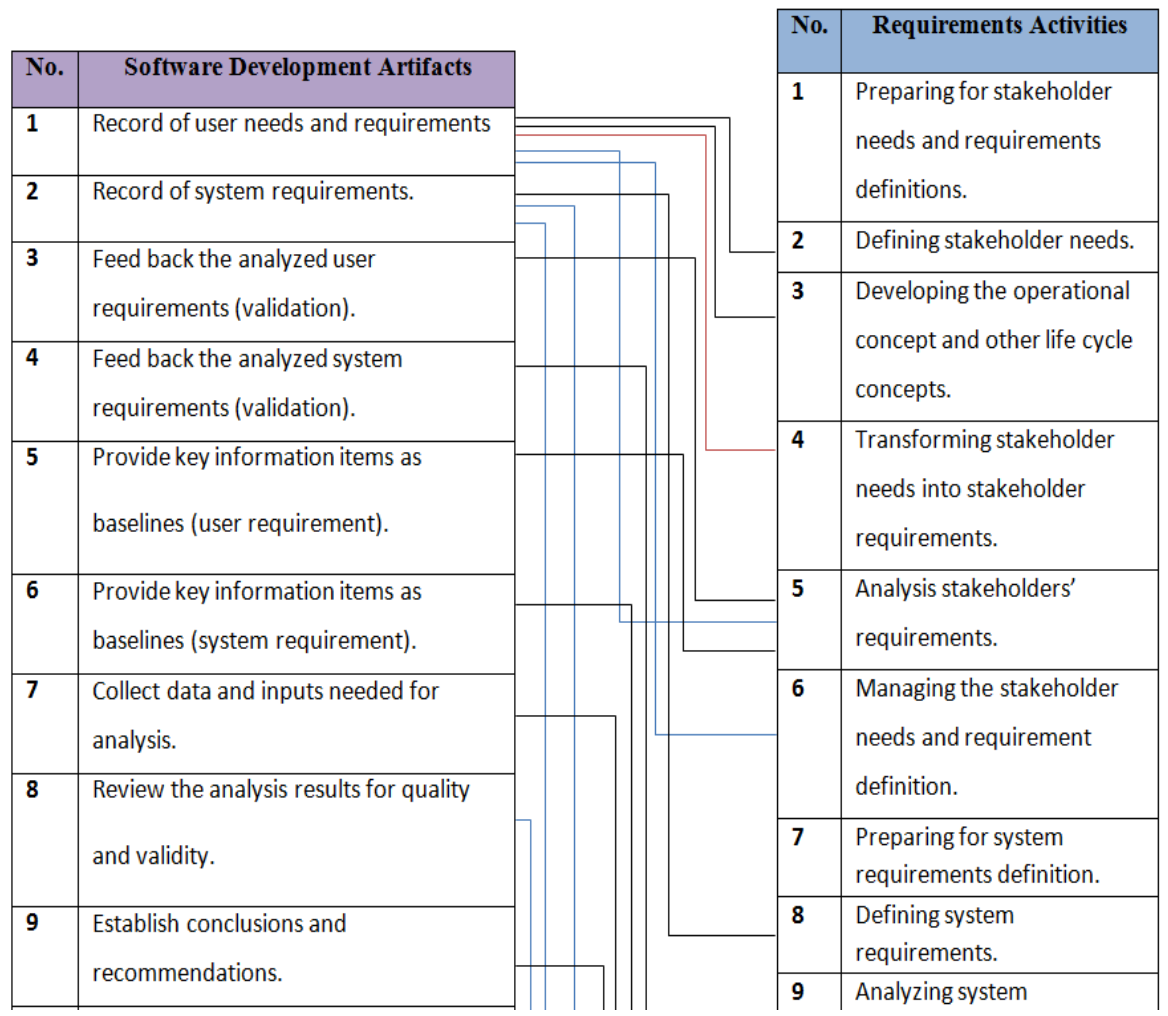

Figure 3. Exchange of information between artifacts and activities

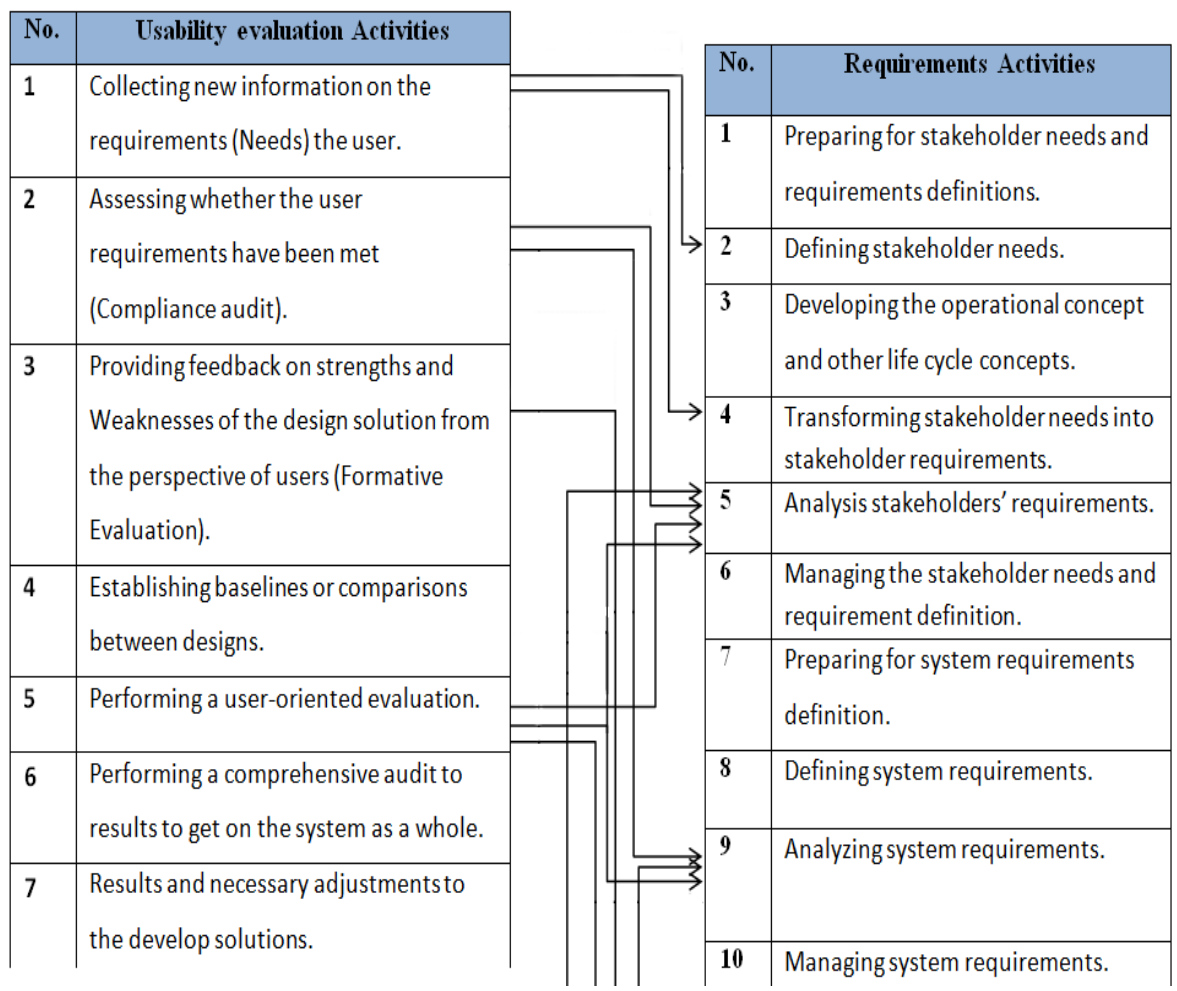

Figure 4. Incorporating usability evaluation into requirements activities 
Consequently, the T-GIUESE model helps organizations to easily compare and discuss their processes. Thus, it simplifies the identification of incorporation aspects between usability evaluation and software development process, with the benefit of compliance to ISO standards and a new, easily followed scheme.

\section{THE KEY CONTRIBUTIONS OF T-GIUESE}

Table 3. Gives a comparison of the proposed tool and international standards

\begin{tabular}{|c|c|c|}
\hline No. & T-GIUESE & Standard \\
\hline 1. & Short and concise & Large and detailed \\
\hline 2. & Specifically identifies integration activities and artifacts. & Determines integration activities and artifacts in general. \\
\hline 3. & $\begin{array}{l}\text { It is collection of figures displaying a map of potential } \\
\text { integration points. }\end{array}$ & $\begin{array}{l}\text { It is a document which provides guidelines over a collection } \\
\text { of clauses. }\end{array}$ \\
\hline 4. & $\begin{array}{l}\text { The relevant parts in the standards ISO/IEC } 15288 \text { and } \\
\text { ISO } 9241 \text { are both represented in this tool. }\end{array}$ & $\begin{array}{l}\text { The standards ISO/IEC15288 and ISO } 9241 \text { are two separate } \\
\text { documents. }\end{array}$ \\
\hline 5. & Free. & Proprietary. \\
\hline
\end{tabular}

T-GIUESE is beneficial from the following aspects (see Table 3):

- To support usability practitioners in the nomination of appropriate activities; as well as documentation and communication of results.

- To define fields of competencies for roles in software development projects to achieve the quality of use.

- To boost the acceptance and understanding of standards related usability evaluation.

- To enable organizations to have clear discussions and comparison of their processes alongside the model, and ultimately identify suitable incorporation aspects.

- To enhance or evaluate the existing process models.

The proposed tool summarizes the aspects in the selected standards relevant to the incorporation of usability evaluation, making it easier for companies to adopt the standards-based usability evaluation. Standards are reliable as they are consensus based and accounts for most current needs of industrial stakeholders. Thus, the standards add value to the incorporation of usability aspects in SMEs as they enable safety, reliability, repeatability of processes, the independence of organizations, good quality, and a basis for communication.

\section{EVALUATION OF T-GIUESE}

This section discusses the evaluation of the proposed tool. The study design in shown is section 6.1 whereas the results are presented in section 6.2.

\subsection{Study Design}

T-GIUESE was evaluated by conducting a questionnaire survey, in line with previous survey studies of evaluation practices [19], [20], [21]. The respondents to this questionnaire survey were from different specializations. The researcher briefed the respondents on the objectives of this study and provided the proposed tool before starting the questionnaire survey.

\subsubsection{Constructs and Items Used}

The questionnaire has been constructed by reviewing previous studies on the evaluation of tools. It comprises of four sections as follows. Firstly, we have the demographic information such as sex, age, job title, and experience in area. The second section evaluates the acceptance of T-GIUESE which involves perceived usefulness and ease of use. The third section evaluates the satisfaction towards the T-GIUESE display. The last section evaluates the quality for each potential incorporation point, basis of artifacts, and convergence artifacts for both usability evaluation and software development. All items used in those sections were scored on a seven-point Likert scale $(7=$ strongly agree; $6=$ very agree; $5=$ agree; $4=$ neutral; 3 = disagree; 2 = very disagree; 1 = strongly disagree).

\subsubsection{Data Collecting}

The researcher contacted potential respondents by telephone and asked their willingness to participate in the survey for a total of 108 respondents. Appointments were made to conduct the face-to-face data collection. This approach was used to ensure a clear understanding of each question and good quality answers from respondents as the researcher is present to give clarification. 


\subsubsection{Reliability}

The cronbach's alpha (a) and the Exploratory Factor Analysis (EFA) were applied to this research to ensure the validity and reliability of the instrument. For reliability, the internal consistency among items in the same construct was tested using the cronbach's alpha coefficient (a), which should be greater than 0.7 to be acceptable as suggested by [22]. The cronbach's alpha value for this study was greater than 0.7 as shown in Table 4, indicating good internal consistency and satisfactory reliability for all constructs.

The underlying structure of each construct was determined by the principal component analysis using Varimax rotation [23]. The principal component analysis depends on the values of factor loadings, which must be greater than 0.7 for each item to be included in the structure of the construct according to [23]. The results in Table 4 showed that all items were loaded on the appropriate factor with values above 0.7 . Then, the correlation between items on individual scales was measured by a convergent validity test, which can be evaluated based on the factor loadings greater than 0.7 as recommended by [24]. As presented in Table 4, the results indicated that the items loadings were above 0.7 ; thus showing good convergent validity for the constructs. In conclusion, the results support the reliability and validity of the questionnaire constructs.

Table 4. Reliability analysis

\begin{tabular}{|c|c|c|c|c|}
\hline Sections & Variables & Items & $\begin{array}{l}\text { Factor Loadings } \\
\text { alpha }(a>70)\end{array}$ & $\begin{array}{c}\text { Cronbach's alpha } \\
(\mathrm{a}>=70)\end{array}$ \\
\hline$\frac{\text { Acceptance of T- }}{\underline{\text { GIUESE Tool }}}$ & $\begin{array}{l}\text { Perceived } \\
\text { Usefulness } \\
\text { Ease of Use }\end{array}$ & $\begin{array}{l}\text { PU1 } \\
\text { PU2 } \\
\text { PU3 } \\
\text { PU4 } \\
\text { PU5 } \\
\text { EU1 } \\
\text { EU2 } \\
\text { EU3 } \\
\text { EU4 } \\
\text { EU5 }\end{array}$ & $\begin{array}{l}.726 \\
.977 \\
.738 \\
.943 \\
.870 \\
.751 \\
.957 \\
.743 \\
.847 \\
.756\end{array}$ & 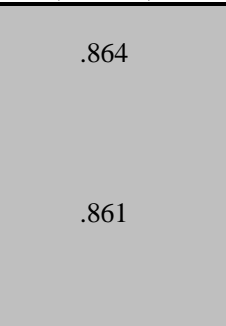 \\
\hline $\begin{array}{l}\text { Display and } \\
\text { Satisfaction } \\
\end{array}$ & $\begin{array}{c}\text { Figures } \\
\text { Satisfaction }\end{array}$ & $\begin{array}{l}\text { F11 } \\
\text { FI2 } \\
\text { FI3 } \\
\text { FI4 } \\
\text { F15 } \\
\text { SA1 } \\
\text { SA2 } \\
\text { SA3 } \\
\text { SA4 } \\
\text { SA5 }\end{array}$ & $\begin{array}{l}.789 \\
.881 \\
.699 \\
.703 \\
.759 \\
.819 \\
.908 \\
.914 \\
.758 \\
.941\end{array}$ & .883 \\
\hline 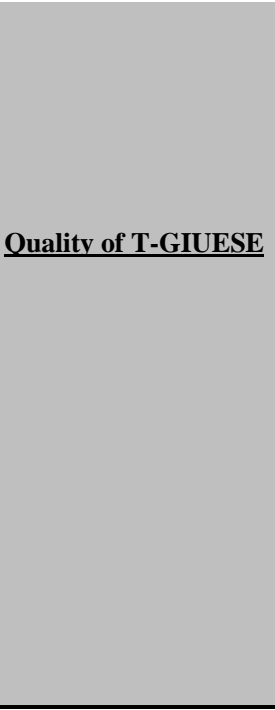 & $\begin{array}{l}\text { The incorporation } \\
\text { points between } \\
\text { activities }\end{array}$ & $\begin{array}{l}\text { IA1 } \\
\text { IA2 } \\
\text { IA3 } \\
\text { IA4 } \\
\text { IA5 } \\
\text { IA6 } \\
\text { IA7 } \\
\\
\text { BA1 } \\
\text { BA2 } \\
\text { BA3 } \\
\text { BA4 } \\
\text { BA5 } \\
\text { BA6 } \\
\text { BA7 } \\
\text { CA1 } \\
\text { CA2 } \\
\text { CA3 } \\
\text { CA4 } \\
\text { CA5 } \\
\text { CA6 } \\
\text { CA7 } \\
\end{array}$ & $\begin{array}{l}.703 \\
.844 \\
.857 \\
.763 \\
.884 \\
.866 \\
.830 \\
\\
.888 \\
.883 \\
.854 \\
.804 \\
.925 \\
.774 \\
.794 \\
.835 \\
.917 \\
.859 \\
.903 \\
.779 \\
.925 \\
.882 \\
\end{array}$ & . \\
\hline
\end{tabular}

\subsection{Results}


The results were presented in the order of the questionnaire sections.

\subsubsection{Demographic Data}

This section discusses the respondents' demographic data and their experience and practices related to software development. Most of the respondents were developers $(36 \%)$, usability engineers $(28 \%)$, and testers $(17 \%)$, while only $(8 \%)$ were project managers and $(11 \%)$ worked in other areas. $(64 \%)$ of the respondents were male and (36\%) were female. The majority of respondents were less than 35 years old $(52 \%)$ while $(39 \%)$ were between $35-45$ years old. Only (9\%) were more than 45 years old (see Figure 5 ).

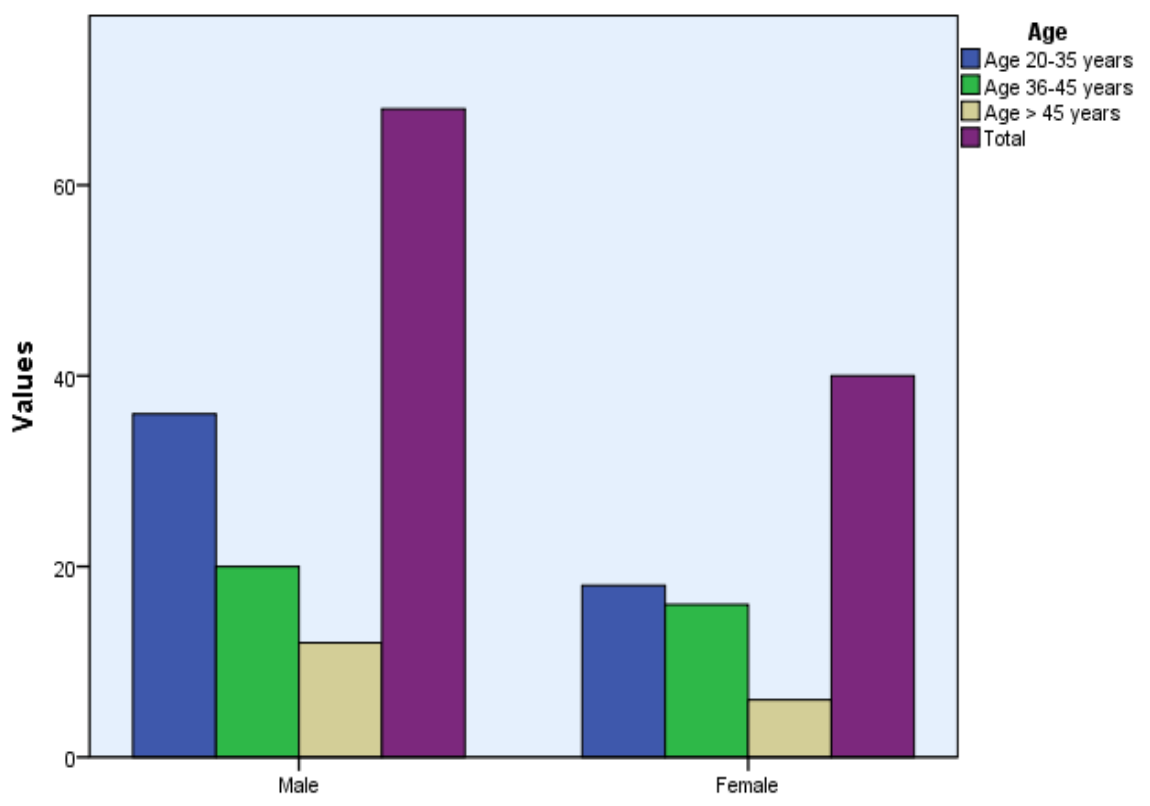

Figure 5. Respondents profile

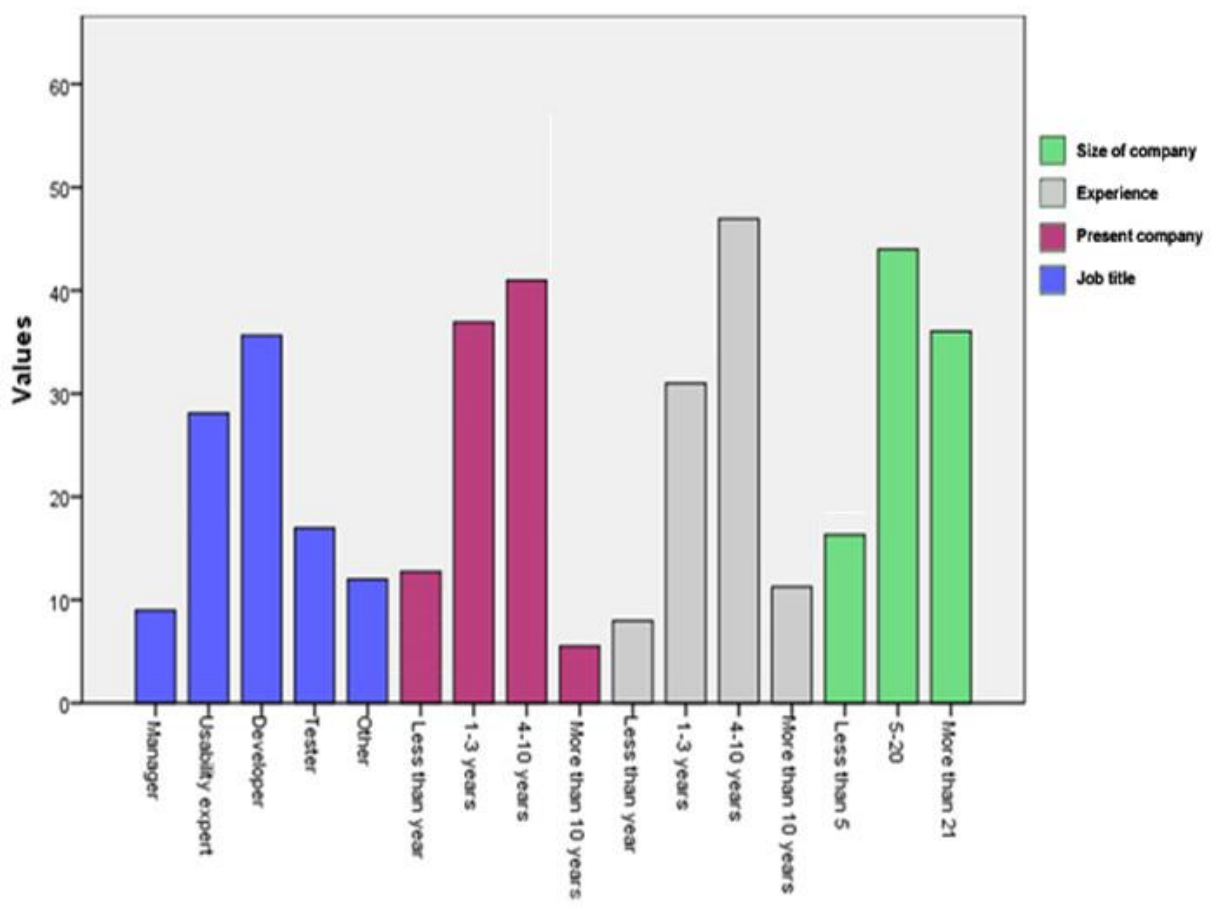

Figure 6. Experience of area 
In terms of experience in software development, (48\%) of the respondents have been involved between 4 and 10 years, whereas (32\%) had less than 3 years of experience. (12\%) have been involved for more than 10 years, but $(8 \%)$ of the respondents reported less than 1 years of involvement. For the duration of employment at their present company, only $(6 \%)$ of the respondents have been reported to have worked for more than 10 years. Most of the respondents were employed between 4 and 10 years (41\%), whereas $(39 \%)$ reported 1 to 3 years. Only $(14 \%)$ of respondents were employed for less than a year at their present companies. Finally, most respondents worked either in small or medium enterprises, of which (18\%) worked in companies with less than 5 employees, and (44\%) in companies with 5 to 20 employees. (38\%) of the respondents work in medium sized companies, defined as organizations with more than 21 employees. Figure 6 depicts the percentage breakdown.

Table 5. Percentage of acceptance and satisfaction variables

\begin{tabular}{cccccccc}
\hline & $\begin{array}{c}\text { Strongly } \\
\text { disagree }\end{array}$ & $\begin{array}{c}\text { Very } \\
\text { disagree }\end{array}$ & Disagree & Neutral & Agree & $\begin{array}{c}\text { Very } \\
\text { agree }\end{array}$ & $\begin{array}{c}\text { Strongly } \\
\text { agree }\end{array}$ \\
\hline $\begin{array}{c}\text { Perceived } \\
\text { Usefulness }\end{array}$ & 2.2 & 4.6 & 6.5 & 14.1 & 16.9 & 26.0 & 29.7 \\
Ease of Use & 1.7 & 6.9 & 6.7 & 9.5 & 28.6 & 21.9 & 24.7 \\
$\quad$ Figures & 2.6 & 8.3 & 13.0 & 9.5 & 19.7 & 22.1 & 24.8 \\
Satisfaction & 3.7 & 5.1 & 6.1 & 11.6 & 17.8 & 26.7 & 29.0 \\
\hline
\end{tabular}

\subsubsection{Acceptance of T-GIUESE}

Sections $\mathrm{B}$ and $\mathrm{C}$ of the questionnaire evaluates the respondents level of agreement with certain features of T-GIUESE, such as perceived usefulness, ease of use, figures, and satisfaction towards the visualization. The participants had to answer structured questions and respond based on a seven point Likert Scale as well as open ended questions as to gather their opinions and suggestions. The participants' responses are explained below;

The results indicate a very strong level of agreement as inferred from the large percentage of "strongly agree" and "very agree" responses to the statement of focused issues as shown in Table 5. Therefore we can conclude that the respondents had very high acceptance to the following aspects of the proposed tool i.e perceived usefulness, ease of use, display and satisfaction. Descriptive statistics were taken to measure the level of each item. A 7 point Likert scale was used for this section, with 7 for "strongly agree" and 1 for "strongly disagree". Any average of above 4.0 was considered to be good as this indicated the level of the respondents' agreement to those statements representing the tested items. Results from the descriptive analysis are shown below: From the descriptive statistics for the item in Table 6, it can be seen that the item with the highest mean (5.35) is "usefulness", and the one with the lowest mean (5.20) is "figures". However, all of these items have a mean of above 4.0 and thus they belong at the same level.

Table 6. Descriptive statistics: mean score of acceptance and satisfaction variables

\begin{tabular}{ccc}
\hline Sections & Mean & Std. Deviation \\
\hline Perceived Usefulness & 5.35 & 1.58 \\
Ease of Use & 5.21 & 1.55 \\
Figures & 5.20 & 1.59 \\
Satisfaction & 5.22 & 1.70 \\
\hline
\end{tabular}

Table 7. Percentage of quality variables

\begin{tabular}{ccccccccc}
\hline & $\begin{array}{c}\text { Strongly } \\
\text { disagree }\end{array}$ & $\begin{array}{c}\text { Very } \\
\text { disagree }\end{array}$ & Disagree & Neutral & Agree & $\begin{array}{c}\text { Very } \\
\text { agree }\end{array}$ & $\begin{array}{c}\text { Strongly } \\
\text { agree }\end{array}$ \\
\hline $\begin{array}{c}\text { The incorporation } \\
\text { activities }\end{array}$ & 4.2 & 5.9 & 8.9 & 13.0 & 20.1 & 25.3 & 22.6 \\
$\begin{array}{c}\text { The basis of artifacts } \\
\text { The convergence artifacts }\end{array}$ & 1.5 & 3.4 & 3.3 & 16.9 & 18.5 & 29.2 & 27.2 \\
\hline
\end{tabular}


Table 8. Descriptive statistics: mean score of quality variables

\begin{tabular}{lcc}
\hline Sections & Mean & Std. Deviation \\
\hline The incorporation activities & 5.05 & 1.68 \\
The basis of artifacts & 5.15 & 1.70 \\
The convergence artifacts & 5.27 & 1.78 \\
\hline
\end{tabular}

\subsubsection{Quality of T-GIUESE}

The quality of T-GIUESE was evaluated by the scales of accuracy, completeness, understandability, sufficience, and relevance. The results indicate a very strong level of agreement inferred from the large percentage of responses with "strongly agree" and "very agree" to the statement of the issue in focus as seen in Table 7. It can be inferred that the respondents evaluated the quality as solid and reliable, with each of the aspects covering potential incorporation points, basis of artifacts, and convergence artifacts forming the basis of the proposed tool.

From Table 8, it can also be seen that the item with the highest mean (5.27) is "The convergence artifacts", and the one with the lowest mean (5.05) is "The incorporation activities". However, all of the items have a mean above 4.0 and thus, they stay on the same level. We can conclude from the results that the respondents regard the surveyed components of the proposed tool as important within the software development process, and viable as a supporting tool to ensure effective and efficient implementation of the usability evaluation activities.

\section{CONCLUSION}

The proposed tool, T-GIUESE makes it easier to apply international standards based usability evaluation within SMEs. The standards (ISO/IEC/IEE 15288, ISO 9241) were represented in the tool, which summarizes the fundamental activities and respective artifacts related to the usability evaluation from key parts of UE, and related to the software development process from key parts of SE. Furthermore, the tool highlights potential incorporation points and links, activities with artifacts to show dependencies and relationships, eventually identifying and showing the convergence artifacts of both disciplines. Finally, this tool was evaluated favourably and it had high acceptance based on the questionnaire survey results involving software development practitioners from SMEs.

\section{ACKNOWLEDGEMENTS}

This research was funded by the Ministry of Education under the Fundamental Research Grant Scheme (FRGS 2013-2), Universiti Malaysia Terengganu.

\section{REFERENCES}

[1] Aykin N, editor. Usability and internationalization of information technology. CRC Press; 2016 Apr 19.

[2] Fernandez A, Insfran E, Abrahão S. Usability evaluation methods for the web: A systematic mapping study. Information and Software Technology. 2011 Aug 31; 53(8): 789-817.

[3] Martinez HS, Rodriguez MD, Dominguez EL. Túum: Test Model for Native Mobile Applications. IEEE Latin America Transactions. 2017; 15(5): 994-1000.

[4] Maciaszek LA, Filipe J, editors. Evaluation of novel approaches to software engineering: 10th International Conference, ENASE 2015, Barcelona, Spain, April 29-30, 2015, Revised selected papers. Springer; 2016 Feb 13.

[5] Fischer H. Integrating usability engineering in the software development lifecycle based on international standards. InProceedings of the 4th ACM SIGCHI symposium on Engineering Interactive Computing Systems 2012 Jun 25 (pp. 321-324). ACM.

[6] Pakistan G, Masood T, Azhar F, Ramzan M, Malik S, Pakistan W. Usability Practices in Software Development Life Cycle: A Review. InProceedings of 2nd International Multi-Disciplinary Conference 19-20 December 2016.

[7] Vila N, Kuster I. The role of usability on stimulating SME's on line buying intention: an experiment based on a ficticius web site design. Quality \& Quantity. 2012 Jan 1; 46(1): 117-36.

[8] Ginige A, Paolino L, Romano M, Tortora G, Vitiello G. ICT for small to medium enterprises: focus on usability for a web-based spreadsheet mediated collaboration environment. In Information systems: crossroads for organization, management, accounting and engineering 2012 (pp. 181-188). Physica-Verlag HD.

[9] Hering D, Schwartz T, Boden A, Wulf V. Integrating usability-engineering into the software developing processes of SME: a case study of software developing SME in Germany. InProceedings of the Eighth International Workshop on Cooperative and Human Aspects of Software Engineering 2015 May 16 (pp. 121-122). IEEE Press. 
[10] Scheiber F, Wruk D, Oberg A, Britsch J, Woywode M, Maedche A, Kahrau F, Meth H, Wallach D, Plach M. Software Usability in Small and Medium Sized Enterprises in Germany: An Empirical Study. InSoftware for people 2012 (pp. 39-52). Springer Berlin Heidelberg.

[11] Ardito C, Baldassarre MT, Caivano D, Lanzilotti R. Integrating a SCRUM-based process with human centred design: an experience from an action research study. InProceedings of the 5th International Workshop on Conducting Empirical Studies in Industry 2017 May 20 (pp. 2-8). IEEE Press.

[12] ISO/IEC/IEEE 15288:Systems and software engineering - System life cycle processes, Genf, 2015.

[13] ISO/IEC 12207: Information technology - Software life cycle processes, Amendment 1. ISO/IEC, Genf, 2002.

[14] ISO/IEC 15504: Information technology - Process Assessment - Part 1-5. ISO/IEC, Genf, 2003-2006.

[15] Nigel Bevan, "International Standards for HCI and Usability", International Journal of Human Computer Studies. 2001, Vol. 55, no. 4, p.p. 533-552.

[16] ISO 9241-210: Human-centered design processes for interactive systems. ISO, Genf, 2010.

[17] ISO TR 16982: Usability methods supporting human-centred design, 2002.

[18] ISO/IEC 14598-6:Software engineering - Product evaluation - Part 6: Documentation of evaluation modules Genf, 2001.

[19] Surendro K, Olivia O. Academic Cloud ERP Quality Assessment Model. International Journal of Electrical and Computer Engineering. 2016 Jun 1; 6(3): 1038.

[20] Roy S, Pattnaik PK, Mall R. A cognitive approach for evaluating the usability of Storage as a Service in Cloud Computing Environment. International Journal of Electrical and Computer Engineering. 2016 Apr 1; 6(2): 759.

[21] Wang C. Assessment of BIM implementation among MEP firms in Nigeria. International Journal of Advances in Applied Sciences. 2015 Sep 1;4(3):73-81.

[22] George D, Mallery P. IBM SPSS Statistics 23 step by step: A simple guide and reference. Routledge; 2016 Mar 22.

[23] Haslwanter T. Multivariate Data Analysis. InAn Introduction to Statistics with Python 2016 (pp. 221-225). Springer International Publishing.

[24] Turner SF, Cardinal LB, Burton RM. Research design for mixed methods: A triangulation-based framework and roadmap. Organizational Research Methods. 2017 Apr; 20(2): 243-67. 